\title{
Chest Computed Tomography of Elderly Subjects at University Hospital Campus Lomé
}

\author{
Pihou Gbande ${ }^{1 *}$, Lantam Sonhaye ${ }^{1}$, Massaga Dagbé ${ }^{2}$, Dagouaba Ouoba1, \\ Lama Kegdigoma Agoda-Koussema ${ }^{3}$, Komlanvi Victor Adjenou ${ }^{1}$ \\ ${ }^{1}$ Radiology Department, Campus Teaching Hospital, Lomé, Togo \\ ${ }^{2}$ Radiology Department, Kara Teaching Hospital, Kara, Togo \\ ${ }^{3}$ Radiology Department, Sylvanus Olympio Teaching Hospital, Lomé, Togo \\ Email: ^gbandepihou@yahoo.fr
}

How to cite this paper: Gbande, P., Sonhaye, L., Dagbé, M., Ouoba, D., Agoda-Koussema, L.K. and Adjenou, K.V. (2018) Chest Computed Tomography of Elderly Subjects at University Hospital Campus Lomé. Open Journal of Radiology, 8, 236-243.

https://doi.org/10.4236/ojrad.2018.84027

Received: October 11, 2018

Accepted: November 16, 2018

Published: November 19, 2018

Copyright (c) 2018 by authors and Scientific Research Publishing Inc. This work is licensed under the Creative Commons Attribution International License (CC BY 4.0).

http://creativecommons.org/licenses/by/4.0/ (c) (i) Open Access

\begin{abstract}
Background: Radiology in elderly as pediatric radiology poses a number of problems. The normal radiological appearance of the elderly patient's chest is very varied and the changes are ubiquitous. Purpose: To describe the computed tomography profile of the elderly subject's chest. Materials and Methods: Descriptive prospective study from January 1st to June 30th, 2018 carried out at the University Campus Hospital of Lomé. Results: We recorded 64 chest CT scans. The average age of the patients was 71.3. Internists $(\mathrm{n}=21,32.8 \%)$ and general practitioner $(\mathrm{n}=16,25 \%)$ were the major applicants for these tests. In most cases, thoracic CT examinations were requested as part of an extension assessment $(n=21,32.8 \%)$, dyspnea and pneumonitis in $18.8 \%$ of cases each. All thoracic CT examinations were performed with contrast injection. CT with the TAP protocol was the most observed, accounted for more than half of the exams (56\%). The main pathological lesions observed were diffuse parenchymal lesions (39.5\%), pleurisy (11.1\%) and PAH (11.1\%). Conclusion: Computed tomography occupies an important place in the care of the elderly but the actors involved in their care must be trained to take optimal care.
\end{abstract}

\section{Keywords}

Computed Tomography, Chest, Elderly, Lomé

\section{Introduction}

According to the World Health Organization (WHO), an elderly person is defined from the age of 60, in Africa [1]. Today, most people have a life expectancy 
of over 60 years. By 2050, the global population aged 60 and over is expected to reach 2 billion, up from 900 million in 2015 [2].

With age, geriatric imaging is characterized by a combination of abnormalities, often normal consequences of aging. In fact, the thorax undergoes, like all the other organs of the body, changes related to aging. Radiology in elderly as pediatric radiology poses a number of problems. The normal radiological appearance of the elderly patient's chest is very varied and the changes are ubiquitous [3].

In Togo, the elderly population is estimated at more than $4 \%$ in 2010 [4] and the care of these people is multidisciplinary. Also we miss studies devoted exclusively to the imaging of the elderly person. The aim of this study was to determine the computed tomography (CT) of the pathological thorax of the elderly at the Lomé University Hospital Center, by determining the qualification of the prescriber for thoracic CT scans of the elderly person and by describing the technical conditions of realization and the main lesions observed.

\section{Materials and Method}

We carried out a prospective study which was held over a period of 6 months, from January to June 2018 in the radiology department of the University Hospital Campus of Lomé. The Campus University Hospital is a national referral hospital and his radiology department performed about 15 CT scans a day.

Included in this study were all thoracic CT scans performed in subjects over 60 years of age during the study period. In this study, we also considered thoracoabdominopelvic CT (TAP-CT) examinations by integrating only the thoracic lesions observed. The exams performed in the context of the surveillance of known pathology are excluded from this study.

The data collection was done using the forms developed for this purpose. These cards included: patient demographics including age and sex, applicant qualification, indications and examination result. All these chest exams were recorded for each working day during the entire duration of the study.

The data collected on the survey cards were analyzed and processed by computer. The computer exploration was done by the software Epi Info 7.

\section{Results}

\subsection{Socio-Demographic Characteristics}

Sixty-four exams were recorded in this study. The average age of the patients was 71.3 years with extremes of 60 and 95 years. The male sex was predominant with 40 men (62.5\%) and 24 women (37.5\%).

\subsection{Profile of Prescriber}

The requests for thoracic CT examinations were made mainly by internist physicians (32.8\%), general practitioners (25\%) and cardiologists in $23.4 \%$ of cases (Table 1). 


\subsection{Indications for Thoracic CT}

Thoracic CT examinations were in most cases requested as part of an extension assessment (32.8\%). Dyspnea and pneumopathy came in 2nd position in $18.8 \%$ each (Table 2).

\subsection{Technicalconditions of Realization}

All thoracic CT examinations were performed with contrast injection. CT with the TAP protocol was the most observed, accounted for more than half of the exams or $56 \%$ (Figure 1).

\subsection{Result of Thoracic CT Exams}

For all the examinations 40 were pathological or $62.5 \%$. The rest of the examinations were normal $(\mathrm{n}=24,37.5 \%)$.

The main pathological lesions observed were: diffuse parenchymal lesions (Figure 2) in 39.5\% of cases, pleurisy (11.1\%) and pulmonary arterial hypertension (Figure 3 ) in $11.1 \%$ of cases. All lesions were listed in Table 3.

\section{Discussion}

\subsection{Study Population}

Sixty-four thoracic CT scans were recorded in this study. The average age of the

Table 1. Distribution of applicants for thoracic CT scans by specialty.

\begin{tabular}{ccc}
\hline & Number & Percentage \\
\hline Cardiologist & 15 & $23.4 \%$ \\
Surgeon & 1 & $1.6 \%$ \\
Internist & 21 & $32.8 \%$ \\
General practitioner & 16 & $25 \%$ \\
Neurologist & 11 & $17.2 \%$ \\
Total & 64 & $\mathbf{1 0 0 \%}$ \\
\hline
\end{tabular}

Table 2. Distribution of indications for thoracic CT.

\begin{tabular}{ccc}
\hline & Number & Percentage \\
\hline Hemoptysis & 4 & $6.3 \%$ \\
Dyspnea & 12 & $18.8 \%$ \\
Chest pain & 1 & $1.6 \%$ \\
Extension report & 21 & $32.8 \%$ \\
Suspicion of pulmonary embolism & 7 & $10.9 \%$ \\
Mediastinal mass & 7 & $10.9 \%$ \\
Pneumopathy & 12 & $18.8 \%$ \\
Total & 64 & $100 \%$
\end{tabular}




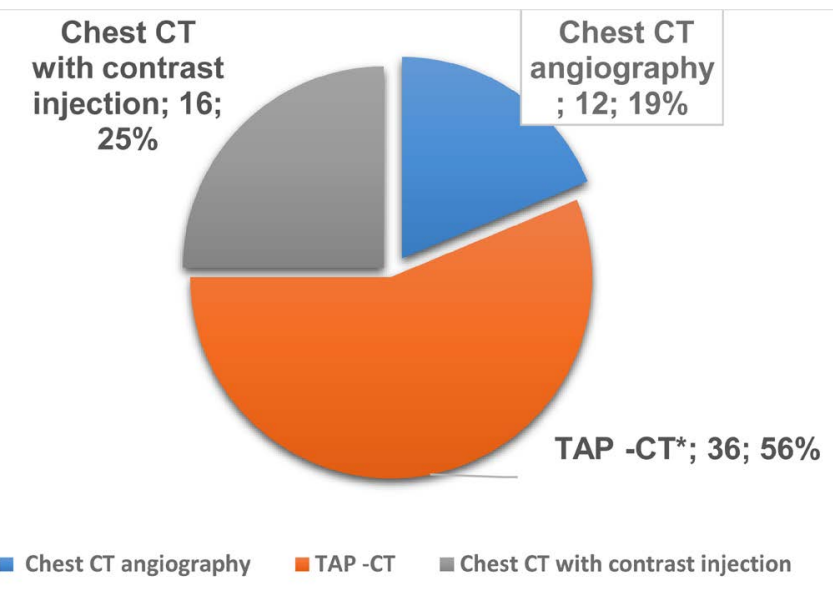

Figure 1. Distribution of chest CT exams according to the protocols. ${ }^{\star} \mathrm{TAP}-\mathrm{CT}=$ Thoracoabdominopelvic CT.

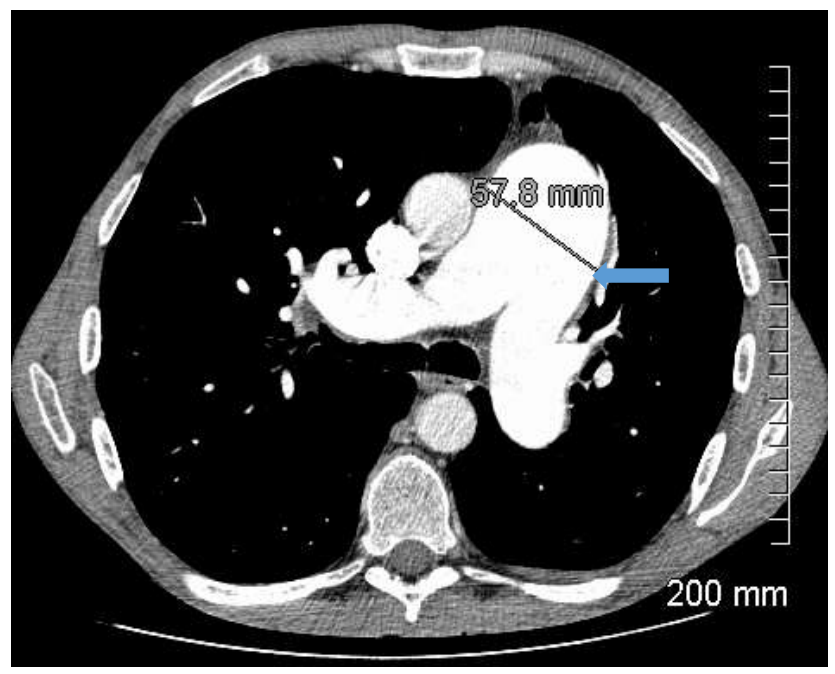

Figure 2. Pulmonary artery trunk (arrow) dilatation measured at $57 \mathrm{~mm}$ reflecting pulmonary arterial hypertension.

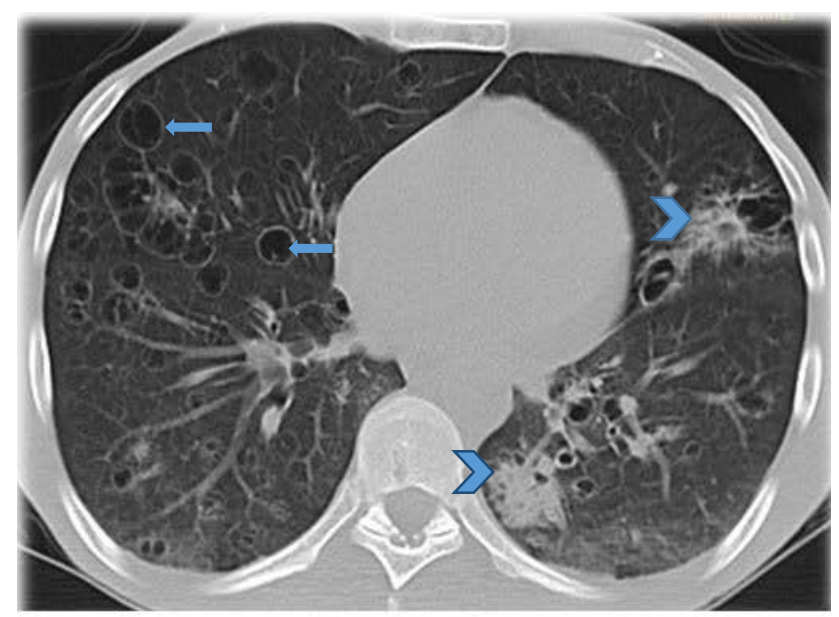

Figure 3. Reticulonodular opacities (arrows head) associated with multiple parenchymal cysts (arrows). 
Table 3. Results of chest CT examinations.

\begin{tabular}{ccc}
\hline & Number & Percentage \\
\hline Pleurisy & 9 & $11.1 \%$ \\
Pneumothorax & 2 & $2.5 \%$ \\
Sequelal lesions & 3 & $3.7 \%$ \\
Mediastinal lymphadenopathy & 6 & $7.4 \%$ \\
Pulmonary embolism & 1 & $1.2 \%$ \\
Bone injury & 2 & $2.5 \%$ \\
Diffuse parenchymal lesions & 32 & $39.5 \%$ \\
Pulmonary nodule & 2 & $2.5 \%$ \\
Emphysema & 5 & $6.2 \%$ \\
Bronchiectasis & 5 & $6.2 \%$ \\
Lesions of the soft parts & 1 & $1.2 \%$ \\
Broncho-oesophageal fistula & 2 & $2.5 \%$ \\
Aneurysm of the thoracic aorta & 2 & $2.5 \%$ \\
Pulmonary arterial hypertension & 9 & $11.1 \%$ \\
\hline
\end{tabular}

patients was 71.3 years with extremes of 60 and 95 years. The male sex was predominant with $62.5 \%$. Zeh et al. in Cameroon had found a similar result with $63 \%$ of men in their series [5]. Adeneji-Sofoluwe et al. had also a male predominance with $63.1 \%$ of men [6]. Men would be more exposed to thoracic pathologies requiring CT scanning than women in old age. Indeed, men are more addicted to smoking, alcoholism or intoxication of the drug than women, risk factors for tumors.

\subsection{Profile of Chest CT Exams Prescriber}

In this study, internist physicians expressed more demand for thoracic CT with a rate of $32.8 \%$; followed by general practitioners (25\%), and cardiologists $(23.4 \%)$. Adeniji-Sofoluwe et al. had also found a predominance of internist physicians in a proportion of $47.1 \%$ [6]. We had not received a request for thoracic CT from pulmonologists for the duration of this study. These results differ widely from those of Awana et al. where pulmonologists were the largest providers of chest CT followed by general practitioners with respective percentages of 27.2 and $18.6 \%$ [7]. The paradox is that no chest CT performed during this study had been requested by a pulmonologist. This result can be explained, on the one hand, by the absence of a pulmonology department at the Lomé Campus University Hospital, with internist and general practitioners playing this role. On the other hand, the comorbidities often observed in these elderly people, which had to be managed by a geriatrician, are provided by the internist doctors.

\subsection{Indications of Chest CT Exams}

In most cases, thoracic CT examinations were requested as part of an extension 
assessment (32.8\%). These examinations are often requested in association with the abdomen and the pelvis. Thus, the TAP-CT protocol was the most used. It represents in this study $56 \%$ of exams. CT is the imaging technique increasingly used for the diagnosis of metastases [8]. Zeh et al. found a much higher proportion with about $45 \%$ of suspected tumors [5]. Detection of pulmonary metastases requires chest radiography and/or thoracic CT. Numerous studies have evaluated the respective efficacy of these two tools for lung metastases. These studies show that chest radiography is often used as a first-line examination. However, $\mathrm{CT}$ is more sensitive than radiography for the detection of pulmonary nodules [9] [10]. Today, with CT in helical mode, more small nodules are detected.

\subsection{Technical Conditions of Realization}

All computed tomography examinations were performed with injection of contrast medium. This does not seem to us totally justified. In fact, nearly $1 / 5$ of the examinations were requested just as part of the exploration of pneumopathy. Contrast injection could be avoided in some of this class of patients. According to the French radiology society, chest CT can be performed without injection of contrast medium, if the objective is only the search for pulmonary parenchymal abnormality (nodule, condensation, bronchiectasis, diffuse infiltrative pneumopathy...) [11]. The study of the pulmonary parenchyma itself does not require intravenous contrast. Contrast injection is reserved for vascular pathology, serous studies, and certain oncological and infectious indications [12]. The injection protocol can be adapted according to the indication and the compartment to be explored.

\subsection{Result of Chest CT Scan}

For all the examinations carried out, $62.5 \%$ were pathological. The rest of the exams were normal (37.5\%). Zeh et al. had found $17 \%$ of normal examinations for all thoracic CT exams performed in university hospitals in Yaoundé without age restriction [5]. This difference may pose a problem of not justifying certain CT examinations carried out in our service. Indeed, thoracic CT is a second intension examination in front of any pneumological symptom, the chest X-ray having to be realized in 1st intention. However, the value of the negative examination should not be underestimated.

The pathological lesions observed were dominated by diffuse parenchymal lesions $(39.5 \%)$. It is a heterogeneous group of pulmonary diseases whose commonality is to be the manifestation of an abnormal tissue response that is exclusively or predominantly in the interstitium, in most cases reaching the alveolar and capillary structures. These lesions could be associated with others such as bronchiectasis and lymphadenopathy. The analysis of multiple pulmonary parenchymal abnormalities in thoracic CT is a real diagnostic challenge. In fact, these abnormalities may be the consequence of a pathology of the pulmonary interstitial tissue, of the tracheobronchial tract, of the cardiovascular system, of a 
hemorrhagic, cellular, or tumoral consolidation, or of several etiologies at once [13].

Pleurisy and pulmonary arterial hypertension (PAH) ranked second after diffuse parenchymal lesions with $11.1 \%$ of cases each. In the Adambounou et al. Series, pleurisy accounted for $23 \%$ of the reasons for hospitalization of elderly subjects in the pulmonology department of SylvanusOlympio University Hospital in Lomé [14]. The high frequency of pleurisy in the elderly can be explained by a decrease in immunity with age, or a history of smoking and alcohol intoxication. It can also be associated with tumors or infection [14].

Pulmonary arterial hypertension is defined by the permanent elevation of pressures in the pulmonary vascular bed. It is defined by WHO as mean pulmonary arterial pressure above $25 \mathrm{mmHg}$ [15]. In the study of Tromeur el al. in France, the prevalence of PAH in the general population was estimated at 25 cases per million inhabitants [15]. The incidence of PAH in its idiopathic form would be of the order of 2 cases per million inhabitants per year, which would represent 100 to 200 new annual cases in France [16]. Thoracic CT angiography has become an essential examination in the diagnosis of PAH. It allows not only to look for signs of positive diagnosis but also to make an assessment of extension (aetiological assessment) and an evaluation of the pulmonary parenchyma [11] [15] [17]. The gold standard examination of this condition is certainly right heart catheterization [11] but it is limited in the etiological research of this affection.

\section{Conclusion}

Computed tomography occupies an important place in the management of the thoracic pathology of the elderly. It is often requested in the assessment of extension of malignant tumors and by internist doctors. Parenchymal lung lesions, pleurisy and pulmonary arterial hypertension are the most observed abnormalities.

\section{Conflicts of Interest}

The authors do not declare any conflict of interest.

\section{References}

[1] Organisation Mondiale de la santé (2002) Proposed Working Definition of an Older Person in Africa for the MDS Project. http://www.who.int/healthinfo/survey/ageingdefnolder/en/

[2] Organisation Mondiale de la Santé (2018) Aging and Health. http://www.who.int/mediacentre/factsheets/fs404/fr

[3] Yernault, J.C. and Scillia, P. (2002) Clinical and Radiological Aspects of the Aging of the Respiratory System. Revue des Maladies Respiratoires, 19, 481-489.

[4] Direction Générale de la Statistique et de la Comptabilité Nationale (2010) Résultats définitifs détaillés du 4ème RGPH, Vol. 2. Lomé.

[5] Zeh, O.F., Awana, A.P., Guegang Goujou, E., Onguene Medza, J., Abomo Ngodo, 
C.S.R., Seme Engoumou, A.M., et al. (2017) Evaluation of the Use of Chest CT in Two University Hospitals in Yaounde. Journal Africain d'Imagerie Médicale, 9, 1-5.

[6] Adeniji-Sofoluwe, A.T., Adekanmi, A.J. and Efidi, R. (2017) Imaging Findings in Chest Computed Tomography: Initial Experience in a Developing Country. Open Journal of Clinical Diagnostics, 7, 113-123. https://doi.org/10.4236/ojcd.2017.74012

[7] Awana, A.P., Engoumou, A.M.S., Onguene Medza, J., Ndive, E.P., Zeh, O.F., Ongolo Zogo, P., et al. (2018) Relevance of Chest CT Scan Requests in Two University Teaching Hospitals in a Developing Country. Open Journal of Radiology, 8, 84-90. https://doi.org/10.4236/ojrad.2018.82010

[8] Gallix, B. (2003) What Are the Exams to Be Carried Out in the Pre-Therapeutic Extension Assessment? Quality Criteria and Expected Results. Gastroentérologie Clinique et Biologique, 27, B25-B40.

[9] Snyder, B.J. and Pugatch, R.D. (1998) Imaging Characteristics of Metastatic Disease to the Chest. Chest Surgery Clinics of North America, 8, 29-48.

[10] Davis, S.D. (1991) CT Evaluation for Pulmonary Metastases in Patients with Extrathoracic Malignancy. Radiology, 180, 1-12. https://doi.org/10.1148/radiology.180.1.2052672

[11] Chassagnon, G., De Margerie-Mellon, C., Perignon, R. and Ferretti, G. (2017) Mémo de l'interne de radio, Le Collège des Enseignants de Radiologie de France (CERF), La Société Française de radiologie (SFR).

[12] Beigelman-Aubry, C. and Brun, A.-L. (2018) How Do I Do a Chest CT. Journal d imagerie diagnostique et interventionnelle, 1, 225-228. https://doi.org/10.1016/j.jidi.2018.06.004

[13] Baqué-Juston, M., Mondot, L., Leroy, S. and Padovani, B. (2014) Multiple Pulmonary Parenchymal Abnormalities. Journal de Radiologie Diagnostique et Interventionnelle, 95, 363-379. https://doi.org/10.1016/j.jradio.2013.03.008

[14] Adambounou, A.S., Adjoh, K., Hamadou, B.B., Fiogbé, A.A., Aziagbé, A., Efalou, P., et al. (2015) Etiologies of Pleurisy of Elderly in Togo. European Scientific Journal, $11,122-131$.

[15] Tromeur, C., Pouliquen, M.-C., Paleiron, N. and Montani, D. (2012) Pulmonary Arterial Hypertension. Médecine Thérapeutique, 18, 125-135.

[16] Gut-Gobert, C., Frachon, I., Jobic, Y., Etienne, Y., Couturaud, F., Pasquier, E., et al. (2005) Therapeutic Strategy in Adult Pulmonary Arterial Hypertension. Médecine Thérapeutique, 11, 45-55.

[17] Sanchez, O., Revel, M. P., Couchon, S. and Meyer, M. (2007) Imaging of Pulmonary Arterial Hypertension in Adults. Revue des Maladies Respiratoires, 24, 155-169. https://doi.org/10.1016/S0761-8425(07)91039-6 